\title{
Physical, chemical, and mineralogical characteristics of blast furnace slag on durability of concrete
}

\author{
Elakneswaran Yogarajah *, Toyoharu Nawa, Toshifumi Igarashi
}

Division of Sustainable Resources Engineering, Faculty of Engineering, Hokkaido University, Kita 13, Nishi 8, Kita-ku, Sapporo, 0608628, Japan

\begin{abstract}
A partial replacement of Portland cement (PC) by ground granulated blast furnace slag (GGBFS) is an effective method to improve the durability of concrete due to its lower diffusivity and higher chemical resistance compared to PC. Further, the microstructure of GGBFS blended cementitious materials controls the physicochemical properties and performance of the materials in concrete. Therefore, understanding of cement hydration and cementing behavior of GGBFS is essential to establish microstructure property relationship for predicting performance. In this study, hydration, microstructure development, and chloride ingress into GGBFS-blended cement have been investigated. Solid-phase assemblage and pore solution chemistry of hydrating PC and cement blended with GGBFS were predicted using thermodynamic model and compared with experimental data. A mathematical model integrating PC hydration, GGBFS reaction, thermodynamic equilibrium between hydration products and pore solution, ionic adsorption on C-S-H, multi-component diffusion, and microstructural changes was developed to predict chloride ingress into GGBFS blended cementitious materials. The simulation results on chloride profiles for hydrated slag cement paste, which was prepared with $50 \%$ of replacement of PC with GGBFS, were compared with experimental results. The model quantitively predicts the states of chloride such as free, adsorbed on C-S-H, and chemically bound as Friedel's salt.
\end{abstract}

\section{Introduction}

Cementitious materials have been using in various reinforced concrete structural components as well as in nuclear waste repositories [1]. Extensive use of supplementary cementitious materials, such as ground granulated blast furnace slag (GGBFS), fly ash, and silica fume, is anticipated not only to reduce $\mathrm{CO} 2$ footprint of Portland cement (PC) but to achieve better performance of concrete in numerous environments [2]. Concrete made with GGBFS shows better performance than conventional concrete in chloride-rich environments [3]. The slag incorporation into cement reduces the total porosity as well as significantly influences pore size distribution, increases fine pores. Furthermore, it has effect on chloride binding and diffusion. Several factors such as porosity, pore size distribution, tortuosity, mineralogical distribution, and the characteristics of calcium alumino silicate hydrate (C-A-S-H) influence on the ionic transport into slag-blended cementitious materials [4]. Therefore, further study on the properties and performance of the materials is necessary for their successful application in concrete structures. The purpose of this study is to calculate hydrate assemblage and pore solution chemistry of slag containing cementitious materials to predict chloride ingress into the materials. Geochemical code, PHREEQC [5], coupled with empirical expressions for dissolution of clinker minerals and reaction of slag is used to calculate hydration products and pore solution composition, and the determined properties are given to a reactive transport model together with microstructure properties to predict ionic transport into the materials.

\section{Materials and methods}

\subsection{Materials, specimen preparation, and experimental methods}

Hardened cement paste with $100 \%$ of PC and GGBBFS cement paste with slag replacement ratio of $50 \%$ and 70 $\%$ were prepared with the water to binder ratio of 0.5 by weight. Backscattered electron image (BEI), energy dispersive X-ray spectrometry (EDX), electron probe microanalyzer (EPMA), micro-elastic modulus, and thermoporometry measurements were conducted on the cured and exposed specimens. The details of the composition of raw materials and their physical properties as well as the experimental techniques are described in our previous paper [6].

\subsection{Modelling approach and calculation procedure}

\footnotetext{
* Corresponding author: elakneswaran@eng.hokudai.ac.jp
} 
The hydration and reactive transport calculations were performed as presented schematically in Fig 1. Hydration reaction of slag-blended cementitious materials were performed based on the coupled model, which couples geochemical code PHREEQC and Excel which is used to calculate dissolution rate of clinker minerals and slag reaction. Pore solution chemistry, hydrate assemblage, and the composition of C-A-S-H were calculated for the input of PC composition, binder proportions, composition of slag, and mixing conditions. The results are transferred to reactive transport model together with boundary conditions for thermodynamic equilibrium and multispecies transport calculations. The basic theory behind thermodynamic equilibrium reactions, cement hydration, and multi-ionic transport are described in authors' previous works [7-8].

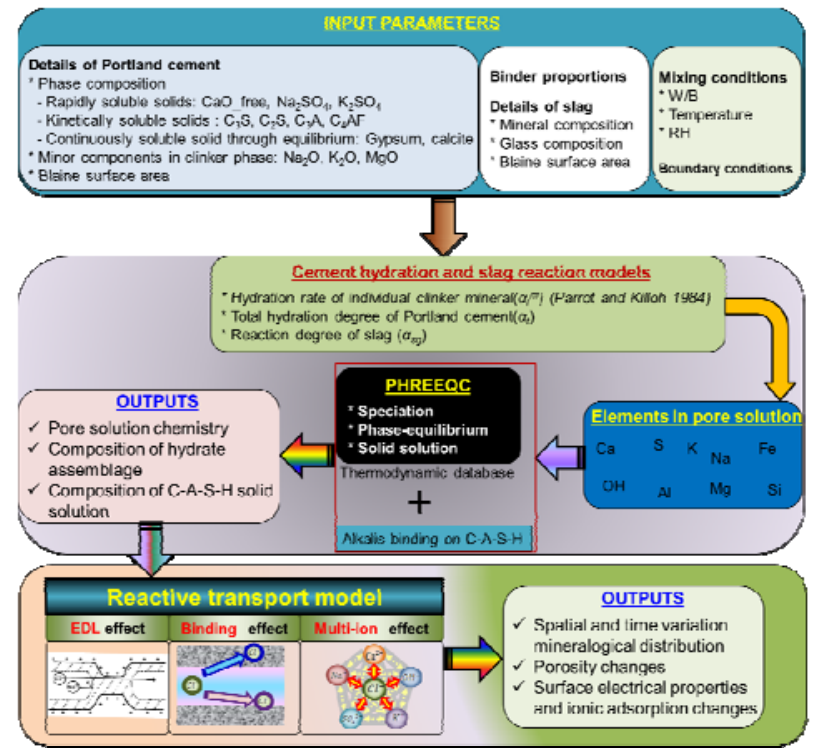

Fig. 1. Calculation procedure of an integrated model

\section{Results and discussion}

\subsection{Hydration products and pore solution chemistry of slag cement system}

The coupled model described in ref [7] with the same database is used in here. The thermodynamic calculations were performed for the hydration reaction of cement clinker minerals and the reaction of slag. It is assumed that only the glass phase of the slag is dissolved uniformly and this reaction does not influence the hydration reaction of the clinker minerals. The reaction of the glass phase and clinkers contribute the kind and amount of hydration products as well as pore solution chemistry. The predicted phase changes in terms of volume and concentration of ions in the pore solution as a function of hydration time for slag-blended cement, which consists of $60 \%$ of PC and $40 \%$ of slag, are shown in Fig. 2. The reaction of clinkers and slag contribute to continuous increase of hydration products and thus decrease of porosity. The main hydration products are $\mathrm{C}$ A-S-H, portlandite, ettringite, hydrotalcite, monosulfoaluminate, and mono and hemicarboaluminate which are due to the presence of calcite in the cement. Further, the ettringite are converted to monosulfoaluminate as the hydration progress. The ionic concentration in the pore solution was calculated based on the release and uptake of alkalis due to the hydration reaction of both $\mathrm{PC}$ and slag. The $\mathrm{Na}, \mathrm{K}, \mathrm{OH}, \mathrm{Ca}, \mathrm{S}, \mathrm{Al}$, and $\mathrm{Si}$ are the major elements in the pore solution. The concentration of alkalis increases with hydration and contributes to high $\mathrm{pH}$ in the pore solution. The mature slag containing cementitious materials have very low concentration of calcium and sulfate ions than alkalis.
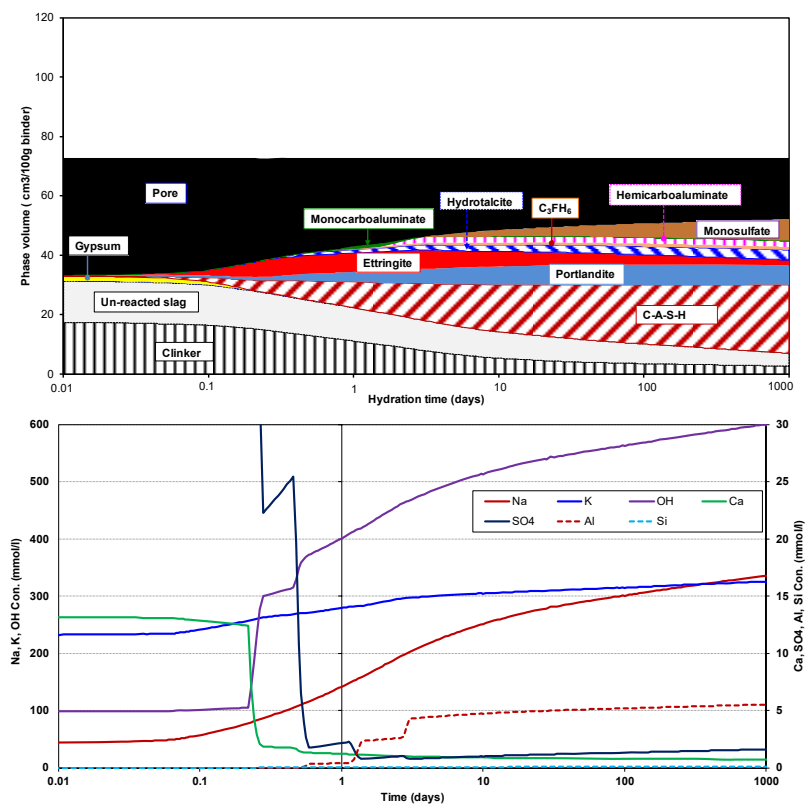

Fig. 2. Simulated phase assemblage in terms of volume and pore solution chemistry of slag-blended cement (PC: Slag $=60: 40$ )

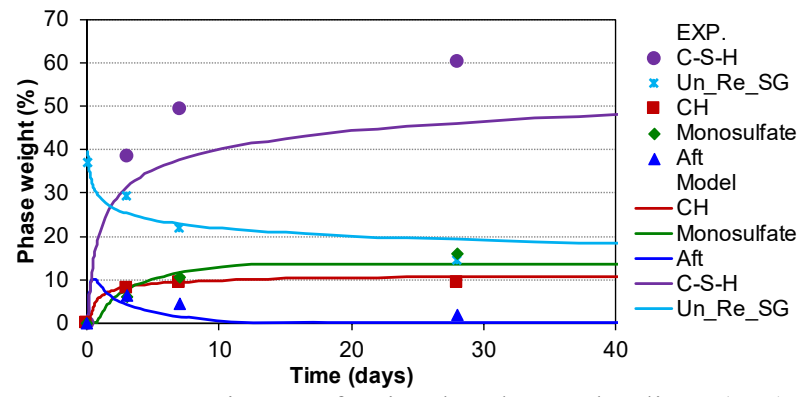

Fig.3. Comparison of simulated portlandite $(\mathrm{CH})$, monosulfate, ettringite (Aft), C-S-H, and un-reacted slag (Un_Re_SG) changes with experimental data [9] for cement blended with slag (OPC: $\operatorname{slag}=60: 40)$ [7].

The simulated hydration products of slag-blended cement were compared with experimental data available in the literature, shown in Fig. 3. The same experimental conditions and the composition of slag and PC were adopted for the simulation [9]. The simulated hydration products agree well with experimental data both qualitatively and quantitatively. However, the model underestimates the amount of C-S-H formed as the hydration of slag and PC. The difference could be attributed by the consideration of the type of endmembers for C-A-S-H solid solution. The hydration model for PC and slag cement system are detailly 
described in our previous work with more experimental verification on hydration products and pore solution chemistry as well as the importance of C-A-S-H solid solution model for cementitious materials [7].

\subsection{Microstructure development of slag cement system}

The pore size distribution of hydrated slag cement paste as determined by thermoporometry is shown in Fig. 4. The pore in cementitious materials are classified as small gel pores $(<5 \mathrm{~nm})$ and large gel pores $(5-10 \mathrm{~nm})$ [10]. The amount of small gel pore increases with slag substitution and it is related to the pores of different C-SHs: low-density C-S-H (LD C-S-H) consists of large gel pores and high-density C-S-H (HD C-S-H) has small gel pores [11]. In the hydrating slag cement system, HD C$\mathrm{S}-\mathrm{H}$ and LD C-S-H are respectively similar to the innerand outer-products of hydrating cement and/or slag [12]. The tortuosity of slag-blended cement paste was determined by fitting the porosity and diffusivity of C-S$\mathrm{H}$, predicted through a three-dimensional spatial distribution model, to Archie's law [13]. The determined tortuosity together with total porosity is tabulated in Table 1. The increase in tortuosity with slag replacement ratio indicates that the diffusion path of chloride ions becomes more complex as more slag is added. Based on the pore size distribution and tortuosity, the critical pore diameter which controls the diffusion is assumed and given in Table 1 . The measured total porosity, tortuosity, and assumed pore radius are used in the prediction of chloride ions diffusion.

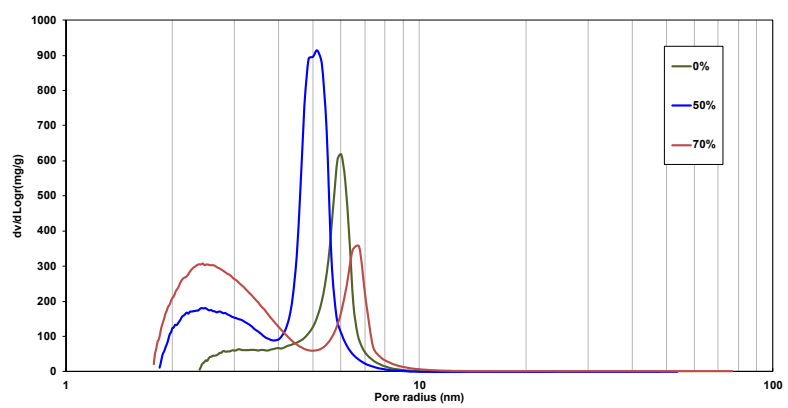

Fig. 4 Pore size distribution of slag-blended cement paste cured at 91 days [6]

Table 1. Porosity, tortuosity, and pore radius used in simulations.

\begin{tabular}{|l|l|l|l|}
\hline $\begin{array}{l}\text { Slag replacement } \\
\text { ratio (\%) }\end{array}$ & Porosity & Tortuosity & $\begin{array}{l}\text { Pore } \\
\text { radius } \\
\text { (nm) }\end{array}$ \\
\hline 0 & 0.200 & 2.39 & 3.2 \\
\hline 50 & 0.214 & 2.63 & 2.3 \\
\hline 70 & 0.226 & 2.85 & 2.1 \\
\hline
\end{tabular}

\subsection{Chloride ingress into slag cement system}

The integrated model developed in a previous work [8] was used to simulate multi-species transport in hydrated slag-blended cement paste sample exposed to $1 \mathrm{~L}$ of 0.5 $\mathrm{mol} / \mathrm{l} \mathrm{NaCl}$ solution for 91 days. The main ions in the pore solution and chloride were considered in the simulation. Initial and final boundary conditions in the simulation were set as exposure solution concentration and zero flux, respectively. As shown in Fig. 1, the pore solution concentration and mineral assemblage were calculated from the hydration model and other microstructure parameters for the simulation are given in Table 1. The simulated total chloride profile is compared with experimental data in Fig. 5. The predicted amounts of chloride in the free water of the pore solution, diffuse double layer, chemically bound as Friedel's salt, and adsorbed on C-S-H surface are also presented. The simulation result agrees well with experimental data indicates that the integrated model could reproduce the experimental data. As can be seen, the physical adsorption of chloride controls the total content, which supports the findings of previous experimental studies in blended cements [14]. Slag-blended cementitious materials have large electrical double layer thickness due to low ionic strength of pore solution as well as high tortuosity and small threshold pore size. They contribute to lower the chloride diffusion in the materials as compared to conventional Portland cement and thus show high durability performance in chloride-rich environments.

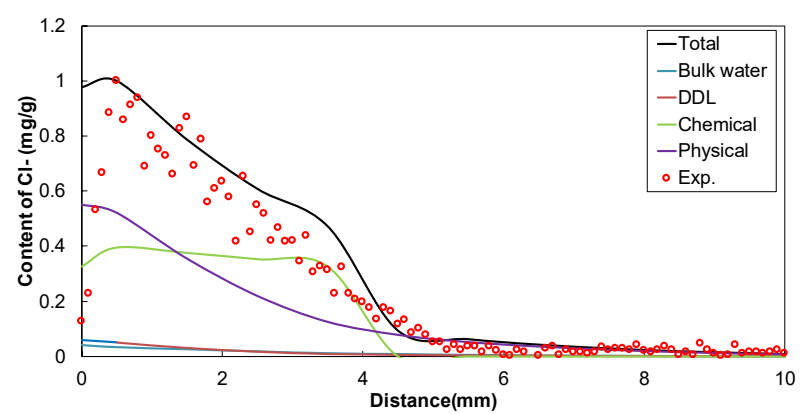

Fig. 5. Comparison between measured and simulated chloride profiles for hydrated slag-blended cement containing $50 \%$ of slag exposed to $0.5 \mathrm{M} \mathrm{NaCl}$ for 91 days. Exp.: Experimentally measured total Cl-; Total: Predicted total Cl-; Bulk water: Predicted free $\mathrm{Cl}-$ in bulk pore water; DDL: Predicted free $\mathrm{Cl}$ - in diffuse double layer; Chemical: Predicted chemically bound Cl-; Physical: Predicted physically adsorbed Cl- on C-S-H [6]

\section{Conclusions}

The chemical thermodynamic equilibrium calculations were performed to predict the solid-phase assemblage and pore solution chemistry of hydrating PC and slag using the coupled model. The agreement between simulation results and experimental data on hydrate assemblage indicates that the model can be used to predict mineralogical distribution and pore solution concentration in slag-blended cement. Integrated model incorporates phase-equilibrium reaction, surface complexation, and multi-ionic transport was applied to predict chloride ingress into hydrated slag cement paste. 
The microstructural properties such as porosity, tortuosity, and threshold pore diameter were determined through experimental results. The chloride profiles predicted by the integrated model agree well with EPMA experimental data for slag-blended cement paste exposed to $0.5 \mathrm{M} \mathrm{NaCl}$ for 91 days. Most of the transported chloride is adsorbed by $\mathrm{C}-\mathrm{S}-\mathrm{H}$ and reduce its concentration in the pore solution as free chloride which causes the reinforcement corrosion. When cement is blended with slag, it modifies mineralogical distribution and surface electrical properties, increases tortuosity, and reduces porosity and threshold pore size to show high chloride resistance and better durability performance.

\section{Acknowledgement}

Authors wish to thank the Japan Cement Association for a part of financial support of this work and Mr. Akira Hatanaka is greatly acknowledged for his assistance in experimental works.

\section{References}

1. Malhorta, V. Durability of Concrete. Corrosion. R. W. Revie Ed.., Wiley. (2000).

2. M.S. Imbabi, C. Carrigan, S. McKenna, Trends and development in green cement and concrete technology, Int. J. Sustain. Built Environ. 1, 194 (2012)

3. H. W Song and V. Saraswathy. Studies on the corrosion resistance of reinforced steel in concrete with ground granulated blast-furnace slag-An overview, Journal of Haz. Materials B 138, 226 (2006)

4. Glasser, Fredrik P., Jacques Marchand, and Eric Samson. Durability of Concrete - Degradation Phenomena Involving Detrimental Chemical Reactions, Cement and Concrete Research 38, 226 (2008)

5. D.L. Parkhust, C.A.J. Appelo, A computer program for speciation, batch- reaction, one-dimensional transport and inverse geochemical calculations, USGS Report, (1999).

6. A. Hatanaka, Y. Elakneswaran, K. Kurumisawa, T. Nawa, The Impact of Tortuosity on Chloride Ion Diffusion in Slag-Blended Cementitious Materials, Journal of Advanced Concrete Technology 15, 426 (2017)

7. Elakneswaran Yogarajah et al. Hydration Study of Slag-Blended Cement Based on Thermodynamic Considerations, Construction and Building Materials 124, 615 (2016)

8. Elakneswaran, Y.et al., Ion-cement hydrate interactions govern multi-ionic transport model for cementitious materials, Cement and Concrete Research 40, 1756 (2010)

9. S. Hoshino, K. Yamada, H. Hirao, XRD/Rietveld analysis of the hydration and strength development of slag and limestone blended cement, J. Adv. Concr. Technol. 4, 357 (2006)

10. Jennings, Hamlin M. Refinements to Colloid Model of C-S-H in Cement: CM-I, Cement and Concrete Research 38, 275 (2008)

11. Tennis, Paul D. and Hamlin M. Jennings. Model for Two Types of Calcium Silicate Hydrate in the Microstructure of Portland Cement Pastes, Cement and Concrete Research 30, 855 (2000)

12. Maekawa Koichi, Tetsuya Ishida, and Toshiharu Kishi. Multi-Scale Modeling of Concrete Performance" Journal of Advanced Concrete Technology 1, 91 (2003)

13. Kurumisawa Kiyofumi, Toyoharu Nawa, and Hitoshi Owada. Prediction of the Diffusivity of Cement-Based Materials Using a ThreeDimensional Spatial Distribution Model, Cement and Concrete Composites 34, 408 (2012)

14. Saeki, T, Sasai, K, Chloride Binding Capacity of Calcium Silicate Hydrate" Cement Science and Concrete Technology. 60, 322 (2006) 